\title{
El "novedoso paradigma" de la recuperación o el descubrimiento del Mediterráneo.
}

\author{
Onésimo González Álvarez. \\ Psiquiatra del S.A.S. \\ onesimo.gonzalez.sspa@juntadeandalucia.es
}

En la introducción al II Plan Integral de Salud Mental de Andalucía 20082012 (PISMA II) se alude al "novedoso paradigma" de la recuperación como una perspectiva que enriquece el modelo comunitario. En publicaciones y encuentros profesionales recientes relativos a la "rehabilitación psicosocial" se alude también a la recuperación ("recovery") como concepto reciente, o como un cambio en el estilo de atención, o un nuevo marco conceptual para la práctica de la rehabilitación.

Shepherd, Boardman y Slade, en 2008 reconocen que muchas de las ideas que fundamentan la filosofía de la recuperación no son nuevas, y refieren antecedentes, desde el "tratamiento moral", pasando por el movimiento de Comunidad Terapéutica (M. Jones), la tradición de rehabilitación inglesa (Bennet) o, en otro plano, los movimientos de consumidores y de derechos civiles en los Estados Unidos (1960 - 1990). Resulta comprensible que desde las organizaciones de usuarios se reivindique la supuesta novedad, ya que no tienen porque conocer la historia de la especialidad ni de la profesión, y porque en la mayoría de los servicios privados y públicos realmente existentes, no se suele ir mas allá de la contención y de la eliminación de síntomas con procedimientos farmacológicos, siendo pocos los que se preguntan por el significado y los motivos de los síntomas, y menos los que se plantean el futuro, la esperanza... Pero los hay, y los ha habido, y su desconocimiento por parte de los profesionales es más que preocupante.

En este punto, el de la esperanza y el futuro (encontrar esperanza y mantenerla es uno de los componentes esenciales del proceso de recuperación) me parece oportuno recordar la aportación de Félix Blanco Caravaca a las primeras Jornadas de la Sección de Psicoanálisis de la A.E.N. (Huelva, 1986) cuando habla del "redesarrollo", "reconstitución", el futuro, la esperanza, "otro posible modo de vivir", o señala las aportaciones de Racamier y de Winnicot, o la necesaria confluencia de ilusión, curiosidad y entusiasmo en terapeuta y paciente, o la atención al saber que está ahí en otros miembros del equipo, como los auxiliares...

El "empowerment" es el otro componente esencial de la recuperación. Se viene traduciendo como "empoderamiento" (se debiera traducir por "involucra- 
ción", según una reciente encuesta de Diario Médico) y se refiere al papel activo de los pacientes o su protagonismo en el proceso de atención. Esta propuesta tampoco es nueva, siendo llamativa la coincidencia de propuestas, principios éticos y normas legales relativas a este protagonismo de los pacientes en torno al año 1978: la Declaración de Alma-Ata (O.M.S. UNICEF, 1978) resulta reiterativa instando a la participación, no solo de los pacientes, sino de todos los individuos y familias de la comunidad... "El pueblo tiene el derecho y el deber de participar individual y colectivamente en la planificación y aplicación de su atención de salud"..., idea central en la definición de Atención Primaria de Salud. El principio ético de autonomía, fundamento del consentimiento informado (Informe Belmont, Informe Beauchamp-Childres) se propugna y difunde en torno al citado año (1974 -1979) y, en nuestro país, de 1978 es la Constitución, cuyo artículo 43, además de reconocer el derecho a la protección de la salud, señala que "la ley establecerá los derechos y deberes de todos al respecto". Una norma legal que precedió en unos meses a la Constitución (R.D. 2082/78) incluye en uno de sus apartados las "garantías de los usuarios", regulación del consentimiento informado que se adelantó 8 años a la Ley General de Sanidad y 24 a la 41/02 de autonomía de los pacientes.

Bienvenida sea esta actitud activa de los usuarios, que hasta el momento, o desconocen el derecho que les asiste o, conociéndolo, no lo han venido ejerciendo.

En otros ámbitos de las actividades sanitarias y sociosanitarias tampoco son nuevos estos principios: La Rehabilitación Médica ha venido fundamentando sus técnicas y procedimientos en la utilización de las partes y funciones sanas, para compensar las ausentes o deterioradas, así como el estímulo a la actividad y protagonismo del paciente.

La integración de la enfermedad en la propia vida concierne a todo tipo de padecimientos crónicos y/o que cursan con déficit o deterioro, y aún mas, una comunidad virtual de discapacitados (Foro de Vida Independiente) pide que se respete el derecho a tomar las riendas de sus propias vidas, y concibe sus limitaciones no como enfermedad, sino como parte de la diversidad y riqueza de la sociedad. 